\title{
AN OPTIMIZATION STUDY ON AN ECO-FRIENDLY ENGINE CYCLE NAMED AS DUAL-MILLER CYCLE (DMC) FOR MARINE VEHICLES
}

\author{
Guven Gonca \\ Yildiz Technical University, Turkey
}

\begin{abstract}
The diesel engine is an indispensable part of technology and it is commonly used in land and marine vehicles. However, diesel engines release $\mathrm{NO}_{x}$ emissions due to high combustion temperatures. They have harmful effects on the environment such as sources of photo-chemical fog and climate changes. Therefore, they must be reduced and limited. The Miller cycle application is a NOx control method and it is popular in the recent years to abate NOx produced from the internal combustion engines (ICEs). A performance investigation of a Dual-Miller cycle (DMC) engine in terms of power (PO), power density (PD) and effective efficiency (EE) has been performed using a new finite-time thermodynamics modeling (FTTM) in this study. The effects of engine design and operating parameters on the engine performance (EPER) have been examined. Additionally, the energy losses have been determined resulting from incomplete combustion (IC), friction (FR), heat transfer (HT) and exhaust output (EO). The results presented could be an essential tool for DMC marine engine designers.
\end{abstract}

Keywords: Dual-Miller cycle engine,Engine performance,Power density,Finite-time thermodynamics

\section{INTRODUCTION}

The ICEs are commonly used in the transport sectors. However, they release pollutant emissions to the atmosphere. One of these pollutant emissions is NOx and it is formed at high combustion temperatures. Miller cycle (MC) application is a method used to abate NOx emission. Miller (1947) developed and applied the MC in a diesel engine to abate compression work. MC was also applied in a gas engine by Miller and Lieberherr (1957). Stebler et al. (1996) performed a numerical and experimental study to show that the MC could abate the NOx produced from a Diesel engine. Clarke and Smith (1997) applied the MC in a diesel engine using an intake control valve. Shimogata et al. (1997) implemented the MC into a gas engine co-generation system and enhanced thermal efficiency and power output of the system. Okamoto et al. (1998) applied the MC and EGR combinations at the different ratios into a gas engine in order to examine the performance variation of the gas engine at stoichiometric combustion conditions. Anderson et al. (1998) analyzed the performance of a MC gasoline engine based on the first and second law of thermodynamics. Wang and Ruxton (2004) reported that NOx formation could be slown down by the application of the MC and it is more eco-friendly compared to other engine cycles. Wang et al. (2005) conducted an experimental work to obtain abatement in NOx of a diesel engine. The NOx formation of a petrol engine by applying the MC with late intake valve closing version (LIVC) was decreased (Wang et al. 2007; Wang et al. 2008). Mikalsen et al. (2009) assessed the potential benefits of the MC application in a natural gas combined system. The cycle performances of the reversible $\mathrm{MC}$ with constant specific heats of working fluid (Al-Sarkhi et al. 2002) and the cycle performance of the reversible and irreversible $\mathrm{MC}$ engines considering temperature-dependent specific heats were analyzed (Al-Sarkhi et al. 2006; Al-Sarkhi et al. 2007). Zhao and Chen (2007) changed pressure ratios of a irreversible MC to assess the cycle performance. The effects of engine speed and temperature-dependent specific heats, relative air-fuel ratio and stroke length on the performance of a reversible MC were examined (Ebrahimi 
2011a; Ebrahimi 2012). According to Rinaldini et al. (2013) study, NOx and soot would be minimized simultaneously in a high-speed DI Diesel engine by applying the MC. Li et al. (2014) proved that MC application could diminish the specific fuel consumption of a gasoline engine. Ge et al. (2005a) used a FTTM so as to examine the effects of FR and HT losses on the performance of an air standard MC. Wu et al. (2003) applied the MC to a supercharged gasoline engine and attained a considerable increase in thermal efficiency. It was proved that the MC application can provide a noticeable reduction in NO formation based on experimental and theoretical studies (Gonca et al. 2013a; Gonca et al. 2013b; Gonca and Sahin 2014; Gonca et al. 2015a; Gonca et al. 2015b; Gonca et al. 2015c; Gonca et al. 2015d; Gonca et al. 2015e). Ust et al. (2015) compared the exergetic performance of the Otto-Miller, Diesel-Miller and DualMiller cycle cogeneration systems. Martins and Lanzanova (2015) applied the MC and EGR together in a gasoline engine fuelled with ethanol and increased the brake efficiency by $47 \%$. Gonca (2016a) compared the performances of the Otto MC, diesel MC and dual MC engines. Gonca (2016b) carried out thermodynamic analysis for the Dual-Atkinson cycle and derived the performance maps. Gonca and Sahin (2016) compared the performance and emission formations of the turbocharged and steam injected MC. Many performance analyses for Dual, Miller and other cycles by using FTT were also performed by the engine researchers described in the literature (Chen et al. 1999; Wu et al. 1999; Wang et al. 2002; Chen and Sun 2004; Ge et al. 2005b; Ge et al. 2005c; Chen 2005; Chen et al. 2006; Ge et al. 2009; Chen et al. 2010; Chen et al. 2011;Gahruei et al. 2013; Chen and Xia 2016; Chen et al. 2016; Ge et al. 2016).

The effects of the engine design and operating parameters on the performance characteristics and energy losses of an DMC engine are reported in this work. Apart from former works, comprehensive comparisons for the engine design parameters are shown by using the included figures. Furthermore, energy losses arising from EO, HT, FR and IC. In this report, realistic performance characteristics named as EE, PO and PD have been used for the DMC engine. The presented results could be assessed by an engine designer to optimize the performance of DMC engines running at lower NOx emissions.

\section{THEORETICAL MODEL}

This study presents a comprehensive analysis for DMC which is depicted in Fig. 1. A numerical simulation of EE, $\mathrm{PO}$ and PD is conducted by using a FTTM. In the performance computations, intake temperature $\left(T_{1}\right)$, intake pressure $\left(P_{1}\right)$, cycle temperature ratio $\left(T_{6} / T_{1}-\alpha\right)$, engine speed $(N)$, friction coefficient $(\mu)$, residual gas fraction (RGF), cylinder wall temperature $\left(T_{W}\right)$, cylinder bore $(d)$ and stroke $(L)$ are defined as follow; $300 \mathrm{~K}, 100 \mathrm{kPa}, 3600 \mathrm{rpm}, 8,12.9 \mathrm{Ns} / \mathrm{m}$, $0.05,400 \mathrm{~K}, 0.072 \mathrm{~m}, 0.062 \mathrm{~m}$ respectively, at the standard conditions.
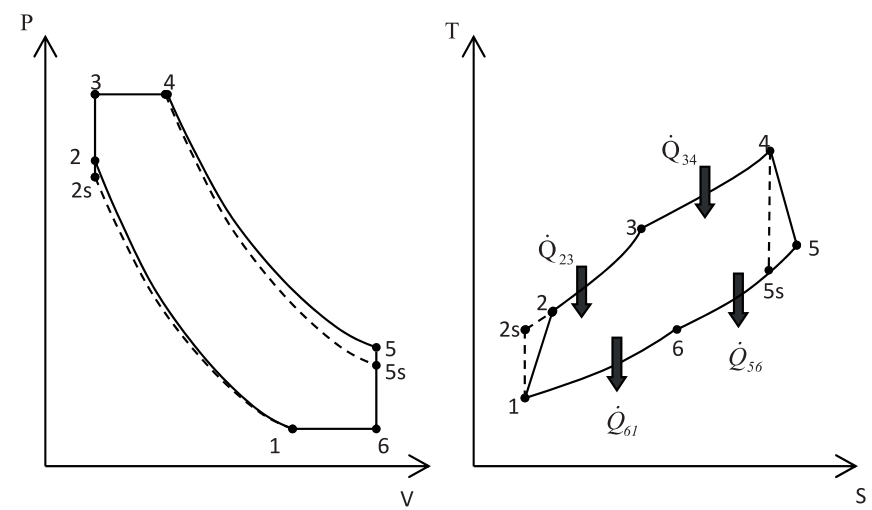

Fig. 1. P-v diagram for the irreversible Dual-Miller cycle (Gonca et al. 2013b).

The PO, PD and EE could be written as:

$$
P_{e f}=\dot{Q}_{i n}-\dot{Q}_{o u t}-P_{l}, P_{d}=\frac{P_{e f}}{V_{T}}, \eta_{e f}=\frac{P_{e f}}{\dot{Q}_{f}}
$$

Where, the total heat addition $\left(\dot{Q}_{i n}\right)$, the total heat rejection $\left(\dot{Q}_{\text {out }}\right)$ and loss power by friction $\left(P_{l}\right)$ (Gonca et al. 2013a; Ge et al. 2008) are given as:

$$
\begin{aligned}
& \dot{Q}_{i n}=\dot{Q}_{f, c}-\dot{Q}_{h t}=\dot{m}_{T}\left[\int_{T_{2}}^{T_{3}} C_{V} d T+\int_{T_{3}}^{T_{4}} C_{P} d T\right]= \\
& \dot{m}_{T}\left(\begin{array}{l}
\left.\left[\begin{array}{l}
2.506 \cdot 10^{-11} \frac{T^{3}}{3}+1.454 \cdot 10^{-7} \frac{T^{2.5}}{2.5}-4.246 \cdot 10^{-7} \frac{T^{2}}{2}+3.162 \cdot 10^{-5} \frac{T^{1.5}}{1.5}+ \\
1.0433 T-1.512 \cdot 10^{4}\left(-\frac{T^{-0.5}}{0.5}\right)+3.063 \cdot 10^{5}\left(-T^{-1}\right)-2.212 \cdot 10^{7}\left(-\frac{T^{-2}}{2}\right)
\end{array}\right)\right]_{T_{2}}^{T_{3}} \\
\left.\left[\begin{array}{l}
2.506 \cdot 10^{-11} \frac{T^{3}}{3}+1.454 \cdot 10^{-7} \frac{T^{2.5}}{2.5}-4.246 \cdot 10^{-7} \frac{T^{2}}{2}+3.162 \cdot 10^{-5} \frac{T^{1.5}}{1.5}+ \\
1.3301 T-1.512 \cdot 10^{4}\left(-\frac{T^{-0.5}}{0.5}\right)+3.063 \cdot 10^{5}\left(-T^{-1}\right)-2.212 \cdot 10^{7}\left(-\frac{T^{-2}}{2}\right)
\end{array}\right)\right]_{T_{3}}^{T_{4}}
\end{array}\right)
\end{aligned}
$$

$$
\begin{aligned}
& \dot{Q}_{\text {out }}=\dot{m}_{T}\left[\int_{T_{6}}^{T_{5}} C_{V} d T+\int_{T_{1}}^{T_{6}} C_{P} d T\right]= \\
& \dot{m}_{T}\left(\left[\begin{array}{l}
\left.\left[\begin{array}{l}
2.506 \cdot 10^{-11} \frac{T^{3}}{3}+1.454 \cdot 10^{-7} \frac{T^{2.5}}{2.5}-4.246 \cdot 10^{-7} \frac{T^{2}}{2}+3.162 \cdot 10^{-5} \frac{T^{1.5}}{1.5}+ \\
1.0433 T-1.512 \cdot 10^{4}\left(-\frac{T^{-0.5}}{0.5}\right)+3.063 \cdot 10^{5}\left(-T^{-1}\right)-2.212 \cdot 10^{7}\left(-\frac{T^{-2}}{2}\right)
\end{array}\right)\right]_{T_{6}}^{T_{5}}+ \\
{\left[\left(\begin{array}{l}
2.506 \cdot 10^{-11} \frac{T^{3}}{3}+1.454 \cdot 10^{-7} \frac{T^{2.5}}{2.5}-4.246 \cdot 10^{-7} \frac{T^{2}}{2}+3.162 \cdot 10^{-5} \frac{T^{1.5}}{1.5}+ \\
1.3301 T-1.512 \cdot 10^{4}\left(-\frac{T^{-0.5}}{0.5}\right)+3.063 \cdot 10^{5}\left(-T^{-1}\right)-2.212 \cdot 10^{7}\left(-\frac{T^{-2}}{2}\right)
\end{array}\right)\right]_{T_{1}}^{T_{6}}}
\end{array}\right)\right.
\end{aligned}
$$

$$
P_{l}=\mu \bar{S}_{P}^{2}=\frac{\left[Z+48\left(\frac{N}{1000}\right)+0.4 \bar{S}_{P}^{2}\right] V_{s} N}{1200}
$$

where $Z$ is a constant relation to friction (Gonca et al. 2013a) and its minimum value is 75 for the diesel engines, where $\mu$ is the friction coefficient, $\bar{S}_{P}$ is the average piston velocity which is :

$$
\overline{\mathrm{S}}_{p}=\frac{L \cdot N}{30}
$$


where $L$ and $N$ are stroke length (m) and speed (rpm). $\dot{Q}_{f}$ is the total heat potential of the fuel injected into the combustion chamber and it is obtained as:

$$
\dot{Q}_{f}=\dot{m}_{f} H_{u}
$$

where $H_{u}$ is the lower heat value (LHV). $\dot{m}_{f}$ is the timedependent fuel mass and it can be expressed as follows:

$$
\dot{m}_{f}=\frac{m_{f} N}{120}
$$

where $m_{f}$ is fuel mass per cycle $(\mathrm{kg}) . \dot{Q}_{f, c}$ is the heat released by combustion; $\dot{Q}_{h t}$ is the heat loss by heat transfer into cylinder wall and they are given as below:

$$
\begin{gathered}
\dot{Q}_{f, c}=\eta_{c} \dot{m}_{f} H_{u} \\
\dot{Q}_{h t}=h_{t r} A_{c y l}\left(T_{m e}-T_{W}\right)=h_{t r} A_{c y l}\left(\frac{T_{2}+T_{4}}{2}-T_{W}\right)
\end{gathered}
$$

where, $\eta_{c}$ is the combustion efficiency. It can be written as (Ebrahimi 2011a; Ebrahimi 2011b; Ebrahimi 2012):

$$
\eta_{c}=-1,44738+4,18581 / \phi-1,86876 / \phi^{2}
$$

$\phi$ is equivalence ratio and it can be written as:

$$
\phi=\frac{\left(m_{f} / m_{a}\right)}{F_{s t}}
$$

where, $m_{a}$ is air mass per cycle $(\mathrm{kg}) . F_{s t}$ is stoichiometric fuel-air ratio and they are given as follows:

$$
\begin{gathered}
m_{a}=\rho_{a} \mathrm{~V}_{a}=\rho_{a}\left(\mathrm{~V}_{T}-\mathrm{V}_{r g}\right) \\
\mathrm{V}_{T}=\mathrm{V}_{s}+\mathrm{V}_{c}=\frac{\left(\mathrm{V}_{s} r\right)}{r-1} \\
V_{c}=\frac{V_{T}}{r}=\frac{\pi d^{2} L}{4} \frac{1}{r-1} \\
F_{s t}=\frac{\varepsilon \cdot(12.01 \cdot \alpha+1.008 \cdot \beta+16 \cdot \gamma+14.01 \cdot \delta)}{28.85} \\
f\left(T_{1}, P_{1}\right)
\end{gathered}
$$

where $\mathrm{V}_{T}, \mathrm{~V}_{a}, \mathrm{~V}_{r g}, \mathrm{~V}_{s}$, and $\mathrm{V}_{c}$ are volume of total cylinder, air, residual gas, stroke and clearance.

$\rho_{r g}$ is density of residual gas which is given as:

$$
\rho_{r g}=f\left(T_{m i x}, P_{1}\right)
$$

$T_{\text {mix }}$ is average temperature of air-steam mixture. They are given as:

$$
T_{m i x}=\frac{\dot{m}_{a} T_{a} R_{a}+\dot{m}_{r g} T_{r g} R_{r g}}{\dot{m}_{a} R_{a}+\dot{m}_{r g} R_{r g}}
$$

$R_{a}$ and $R_{r g}$ are gas constants of air and residual gas. Their values are considered in the calculations as $0.287 \mathrm{~kJ} / \mathrm{kg} . \mathrm{K}$

The compression ratio $(r)$ is given as:

$$
r=V_{1} / V_{2}
$$

Where $f$ means function for the eq. 18. The functional expressions are obtained by using EES software (EES 2016). Fuel used in the model is diesel and its chemical formula is given as $\mathrm{C}_{14.4} \mathrm{H}_{24.9}$ (Ferguson 1986). Where $\alpha, \beta, \gamma, \delta$ are atomic numbers of carbon, hydrogen, oxygen, nitrogen in fuel, respectively. $\varepsilon$ is the molar fuel-air ratio (Ferguson 1986):

$$
\varepsilon=\frac{0,21}{\left(\alpha-\frac{\gamma}{2}+\frac{\beta}{4}\right)}
$$

where, $h_{t r}$ is the heat transfer coefficient and it is stated as (Hohenberg 1979):

$$
h_{t r}=130 \mathrm{~V}_{T}^{-0.06} \mathrm{P}_{1}^{0.8} \mathrm{~T}_{\text {mix }}{ }^{0.4}\left(\overline{\mathrm{S}}_{p}+1.4\right)^{0.8}
$$

$\dot{m}_{T}, \dot{m}_{a}, \dot{m}_{r g}$ and $A_{c y l}$ are flow rate of air-fuel mixture (kg/s), air $(\mathrm{kg} / \mathrm{s})$, residual gas $(\mathrm{kg} / \mathrm{s})$ and heat transfer area of the cylinder (m2), respectively, they are stated as follows:

$$
\begin{gathered}
\dot{m}_{T}=\dot{m}_{a}+\dot{m}_{f}+\dot{m}_{r g} \\
\dot{m}_{a}=\frac{m_{a} N}{120}=\frac{\dot{m}_{f} F_{s t}}{\phi} \\
\dot{m}_{r g}=\frac{m_{r g} N}{120}=\dot{m}_{a} R G F
\end{gathered}
$$




$$
A_{c y l}=\pi d L \frac{r}{r-1}+\frac{\pi d^{2}}{2}
$$

where $m_{s}$ and $m_{r g}$ are air masses per cycle $(\mathrm{kg})$. RGF is the residual gas fraction. $d$ and $r$ are cylinder bore (m) and compression ratio, respectively. $T_{m e}$ and $T_{W}$ are average combustion temperature and cylinder wall temperature. $C_{P}$ and $C_{V}$ are the specific heats of constant pressure and constant volume processes, they are given as (Ge et al. 2008):

$C_{P}=2.506 \cdot 10^{-11} T^{2}+1.454 \cdot 10^{-7} T^{1.5}-4.246 \cdot 10^{-7} T+3.162 \cdot 10^{-5} T^{0.5}$

$+1.3301-1.512 \cdot 10^{4} T^{-1.5}+3.063 \cdot 10^{5} T^{-2}-2.212 \cdot 10^{7} T^{-3}$

$$
C_{V}=C_{P}-R
$$

The equations for reversible adiabatic processes (1-2s) and (4-5s) are respectively as follows (Lin et al. 1999):

$$
C_{V_{1}} \cdot \ln \left|\frac{T_{2 s}}{T_{1}}\right|=R \ln |r|, C_{V_{2}} \cdot \ln \left|\frac{T_{5 s}}{T_{4}}\right|=R \cdot \ln \left|\frac{1}{r}\right|
$$

where,

$C_{V_{1}}=2.506 \cdot 10^{-11} T_{2 s 1}{ }^{2}+1.454 \cdot 10^{-7} T_{2 s 1}{ }^{1.5}-4.246 \cdot 10^{-7} T_{2 s 1}+3.162 \cdot 10^{-5} T_{2 s 1}{ }^{0.5}+$ $1.0433-1.512 \cdot 10^{4} T_{2 s 1}{ }^{-1.5}+3.063 \cdot 10^{5} T_{2 s 1}{ }^{-2}-2.212 \cdot 10^{7} T_{2 s 1}{ }^{-3}$

$C_{V_{2}}=2.506 \cdot 10^{-11} T_{5 s 4}{ }^{2}+1.454 \cdot 10^{-7} T_{5 s 4}{ }^{1.5}-4.246 \cdot 10^{-7} T_{5 s 4}+3.162 \cdot 10^{-5} T_{5 s 4}{ }^{0.5}+$ $1.0433-1.512 \cdot 10^{4} T_{5 s 4}{ }^{-1.5}+3.063 \cdot 10^{5} T_{5 s 4}{ }^{-2}-2.212 \cdot 10^{7} T_{5 s 4}{ }^{-3}$

$$
\begin{gathered}
T_{2 s 1}=\frac{T_{2 s}-T_{1}}{\ln \frac{T_{2 s}}{T_{1}}}, T_{5 s 4}=\frac{T_{5 s}-T_{4}}{\ln \frac{T_{5 s}}{T_{4}}} \\
\beta=P_{3} / P_{2}=T_{3} / T_{2}
\end{gathered}
$$

$\beta$ is named as pressure ratio. For irreversible conditions, $T_{2}$ and $T_{5}$ could be written as (Rashidi et al 2013; Rashidi et al 2014a; Rashidi et al 2014b; Rashidi et al 2014c; Rashidi et al 2014d; Mousapour et al. 2016; Gonca 2017b; Gonca 2017c; Gonca 2017d; Gonca and Sahin 2017b) :

$$
\begin{gathered}
T_{2}=\frac{T_{2 \mathrm{~S}}+T_{1}\left(\eta_{\mathrm{C}}-1\right)}{\eta_{\mathrm{C}}} \\
T_{5}=T_{4}+\eta_{E}\left(T_{5 S}-T_{4}\right)
\end{gathered}
$$

Where $\eta_{C}$ and $\eta_{E}$ are isentropic compression and expansion efficiencies, respectively. In this work, the other dimensionless engine design parameters used in the analysis are cycle temperature ratio (CTR- $\alpha$ ), cycle pressure ratio
$(\mathrm{CPR}-\lambda)$ and cut-off ratio $(\psi)$. They may be expressed respectively as:

$$
\begin{gathered}
\alpha=\frac{T_{\max }}{T_{\min }}=\frac{T_{4}}{T_{1}}=\frac{\lambda}{r} \\
\lambda=P_{\max } / P_{\min }=P_{3} / P_{1} \\
\psi=v_{4} / v_{3}=T_{4} / T_{3}
\end{gathered}
$$

Energy losses could be expressed as percentage of fuel's energy by combustion in combustion chamber of the engine (Lin et al. 2008). In this work, similar approach is used to obtain the energy losses dependent on heat transfer to cylinder wall, exhaust, friction and incomplete combustion presented as:

$L_{h t}=\frac{\dot{Q}_{h t}}{\dot{Q}_{f u e l}} \cdot 100, L_{e x}=\frac{\dot{Q}_{\text {out }}}{\dot{Q}_{\text {fuel }}} \cdot 100, L_{f r}=\frac{P_{u}}{\dot{Q}_{f u e l}} \cdot 100, L_{i c}=\left(1-\eta_{c}\right) \cdot 100$

\section{RESULTS AND DISCUSSION}

In this study, a FTTM has been applied to a DMC engine to evaluate PO, PD and EE. Fig. 2 shows the effects of cycle temperature ratio on the performance characteristics. The maximum EE, PO and PD increase with increasing CTR owing to more energy input into a cylinder.

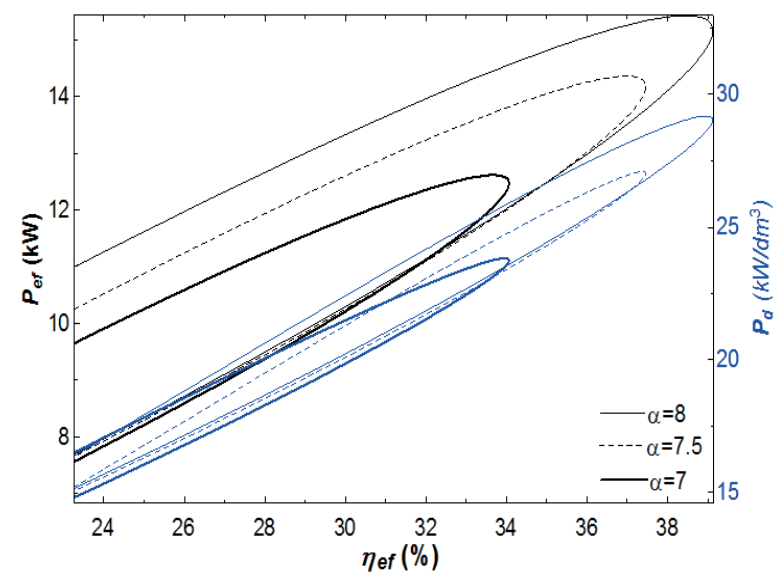

Fig. 2. The variation of $P_{e f}-P_{d}-\eta_{e f}$ with respect to $\alpha$.

Fig. 3 shows the effects of friction coefficient on the performance parameters. The friction coefficient is related to lubrication oil and in-cylinder surfaces in which friction occurs. Friction losses increase with increasing the friction coefficient, hence performance parameters decrease remarkably since irreversibility increases. 


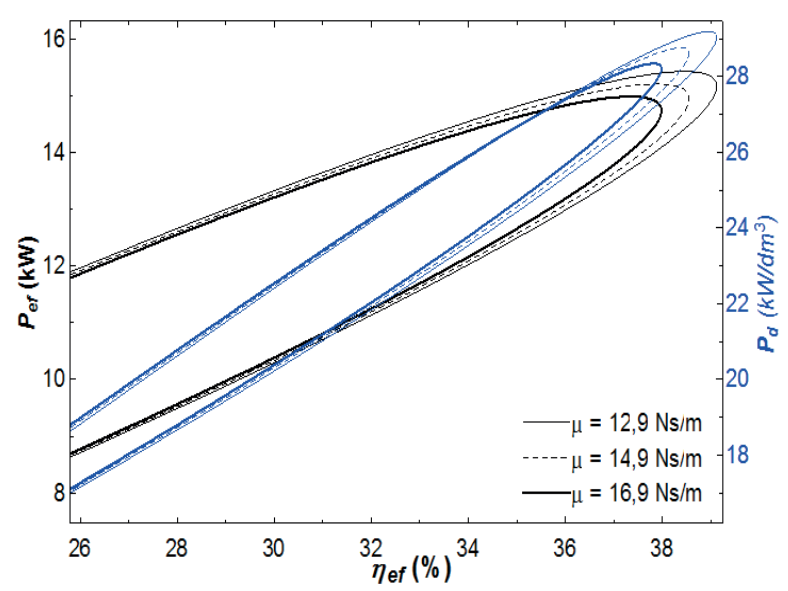

Fig. 3. The variation of $P_{e f}-P_{d}-\eta_{e f}$ with respect to $\mu$.

Fig. 4 illustrates the effects of the engine speed on the performance characteristics. As expected, the PO and PD rise with enhancing speed. However, the effective efficiency is slightly lower at higher engine speeds as the friction losses rise with augmenting engine speeds. It is clear that the raise ratio of fuel energy is slightly higher compared to that of $\mathrm{PO}$ and PD.

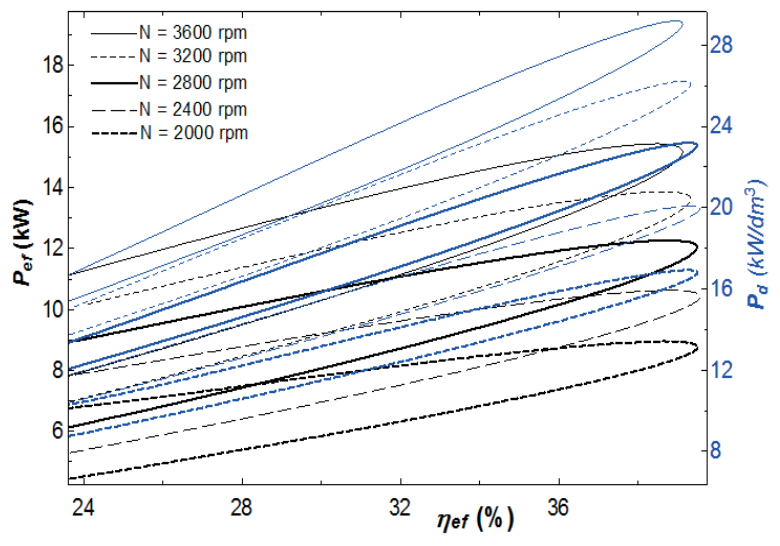

Fig. 4. The variation of $P_{e f}-P_{d}-\eta_{e f}$ with respect to $N$.

Figs. 5 show the influence of mean piston speed on the engine performance. Fig. 5a is plotted at constant engine speed condition. In this figure, it is shown that the performance characteristics rise simultaneously with enhancing mean piston speed because engine dimensions (stroke length and bore) enhance together. Fig. 5b is plotted at constant stroke length condition. As the effective efficiency decreases, the $\mathrm{PO}$ and PD increase with increasing mean piston speed at this condition, since engine speed raises. It is clearly seen that PD change at constant stroke length condition is greater than that at constant engine speed condition, as the change in engine dimensions has similar trend as the change in PO at the constant stroke length condition.
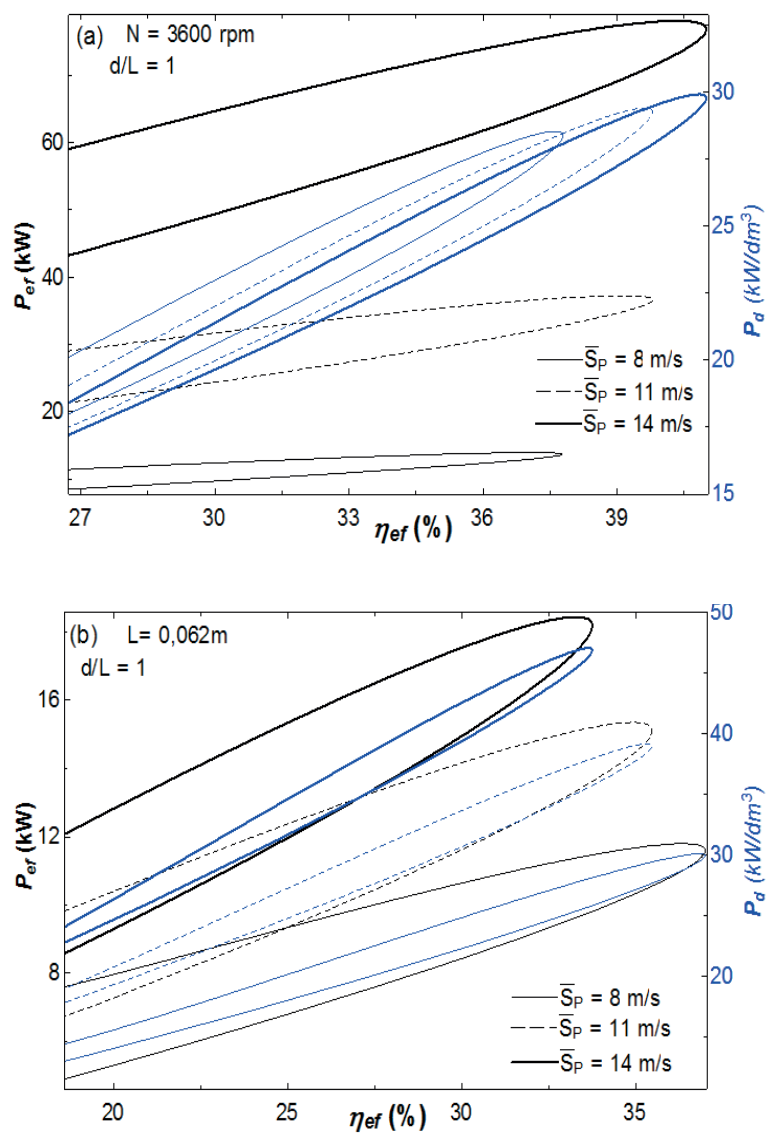

Fig. 5. The variation of $P_{e f}-P_{d}-\eta_{e f}$ with respect to $\bar{S}_{p}$ at constant a) $\left.N, b\right) L$.

Fig. 6 shows the effects of stroke length on the engine performance characteristics. It is clear from the figure that the $\mathrm{PO}$ increases while the EE and PD decrease with enhancing stroke length. The main reason of this result is that the friction losses and engine dimensions increase with respect to stroke length. Although engine power increases, engine dimensions increase more. Therefore, power density decreases with increasing power. Also, it is seen from the figure that the ratio of power change is higher than that of power density.

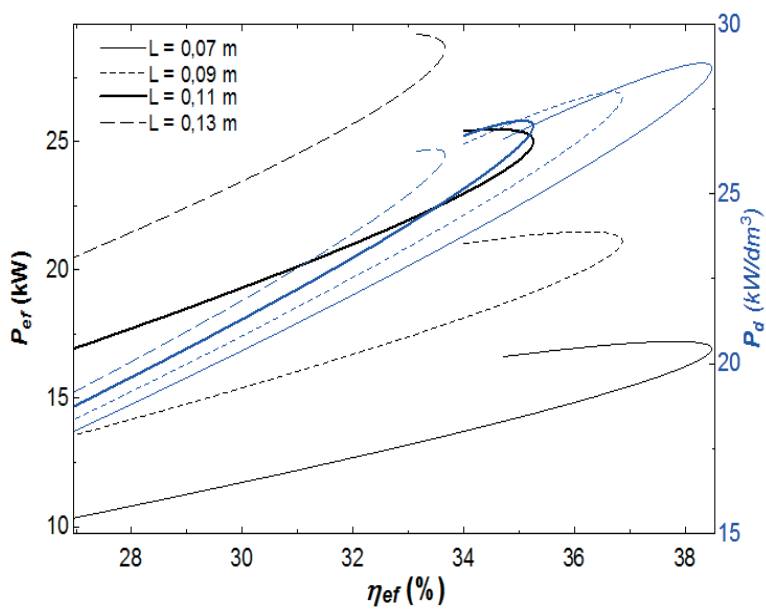

Fig. 6. The variation of $P_{e f}-P_{d}-\eta_{e f}$ with respect to $L$. 
Fig. $7 \mathrm{a}$ and $7 \mathrm{~b}$ show the effects of intake temperature on the engine performance at two different conditions. Fig. 7a is plotted at constant CTR condition. The performance characteristics increase while intake temperature increases since maximum combustion temperature and energy input increase. Fig. $7 \mathrm{~b}$ is plotted at constant maximum combustion temperature condition. The performance parameters minimize with increasing intake temperature since air mass introduced into cylinder minimizes.
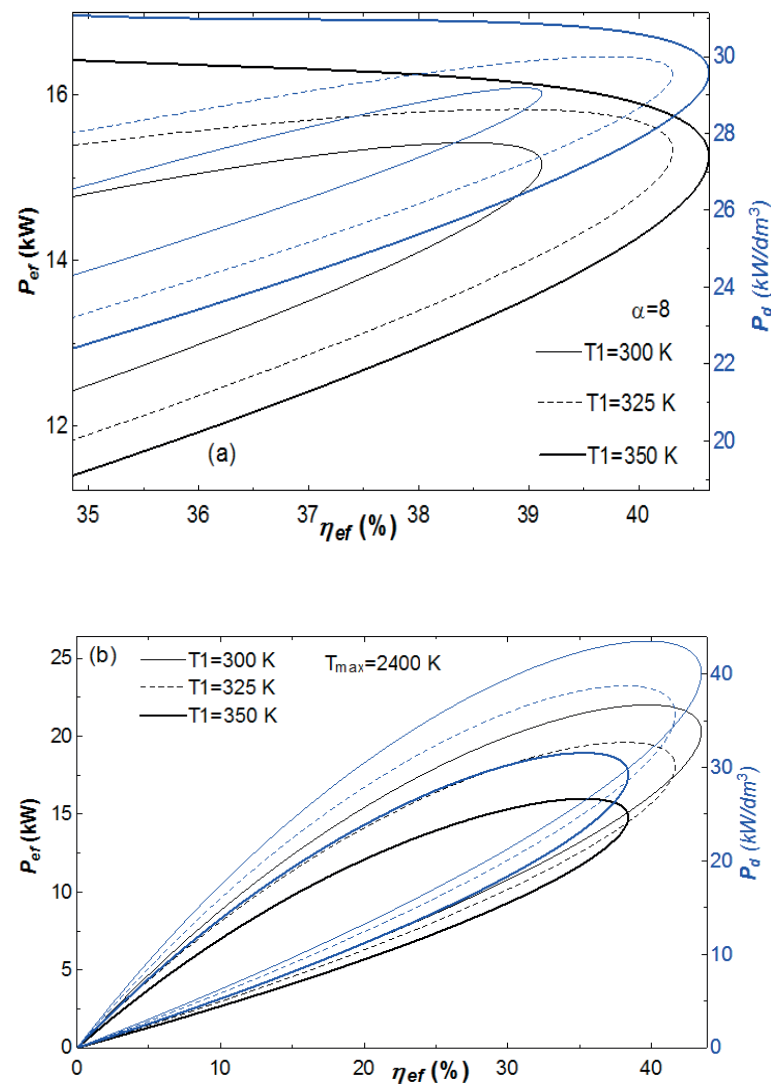

Fig. 7. The variation of $P_{e f}-P_{d}-\eta_{e f}$ with respect to T1 at constant a) $\alpha$ and b) Tmax.

Fig. $8 \mathrm{a}, 8 \mathrm{~b}, 8 \mathrm{c}$ and $8 \mathrm{~d}$ illustrate the influences of equivalence ratio and compression ratio on the CTR and the performance characteristics. The CTR and the performance characteristics enhance with rising compression ratio. However, they rise to a certain value and then begin to abate with rising equivalence ratios. There are optimum values of equivalence ratio which give maximum CTR, PO, PD and EE. Their optimum values are observed at different equivalence ratios. The maximum values of CTR, $\mathrm{PO}$ and $\mathrm{PD}$ are between 1 and 1.2 of equivalence ratio while the maximum value of $\mathrm{EE}$ is between 0.8 and 1 of the equivalence ratio.
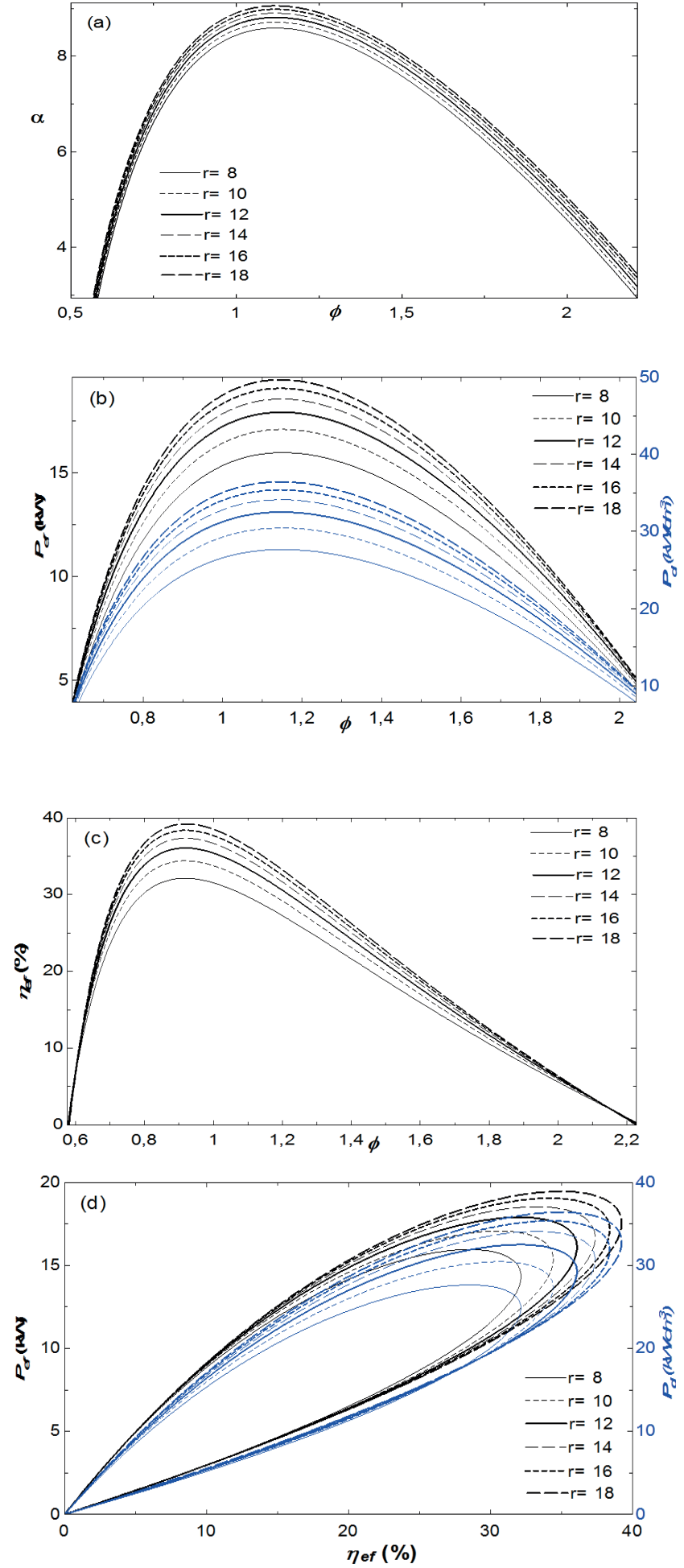

Fig. 8. The variation of $a) \alpha, b) P_{e f}-P_{d}$, c) $\eta_{e f}$ and d) $P_{e f}-\eta_{e f}$ with respect to $r$ and $\phi$.

Fig. 9 shows the influence of equivalence ratio on the engine performance. Similar to previous figures, the performance parameters increase to certain values of equivalence ratio and then start to reduce. The maximum effective efficiency is seen at 0.9 of equivalence ratio while the maximum power is seen at 1.2 of equivalence ratio. 


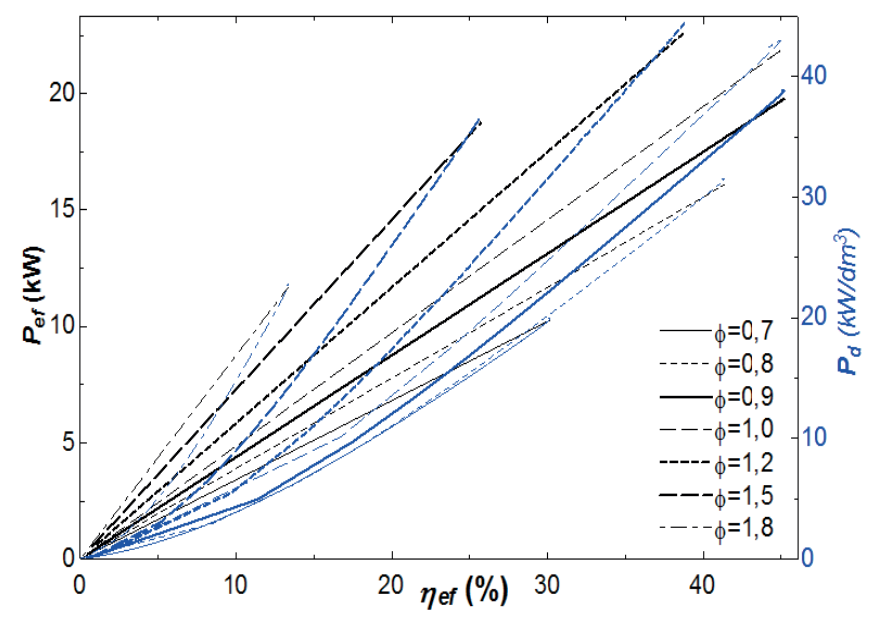

Fig. 9. The variation of $P_{e f}-P_{d}-\eta_{e f}$ with respect to $\phi$.

Fig. 10 shows the effects of cylinder wall temperature on the engine performance. There are no noticeable changes in maximum power and power density depending on cylinder wall temperature. However, maximum effective efficiency decreases with decreasing cylinder wall temperature since heat transfer loss increases with decreasing wall temperature.

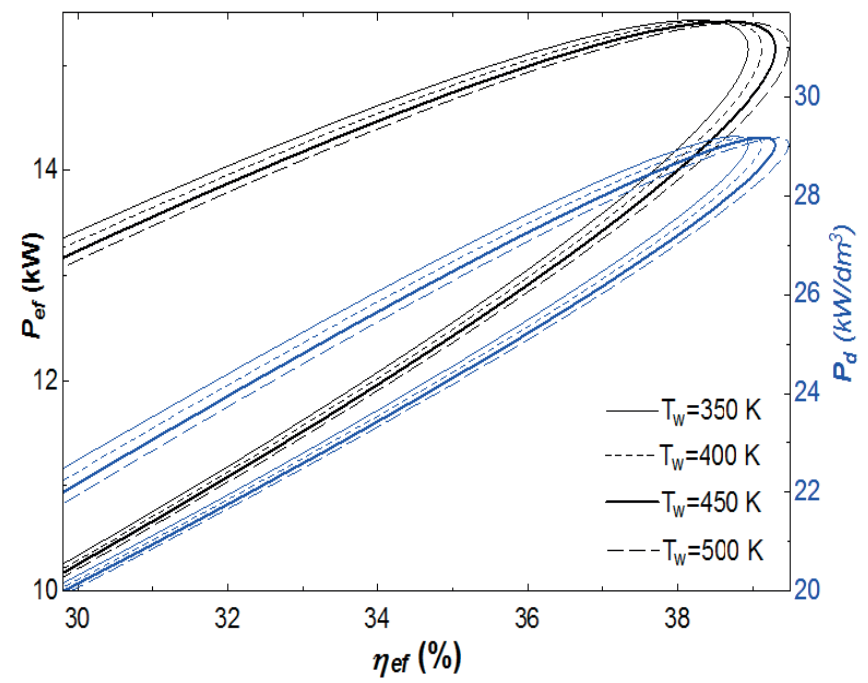

Fig. 10. The variation of $P_{e f}-P_{d}-\eta_{e f}$ with respect to TW.

Fig. 11 demonstrates the influence of intake pressure on the engine performance. It is known that more air mass is introduced into the cylinder at higher pressure conditions. Thus, performance parameters increase with raising intake pressure.

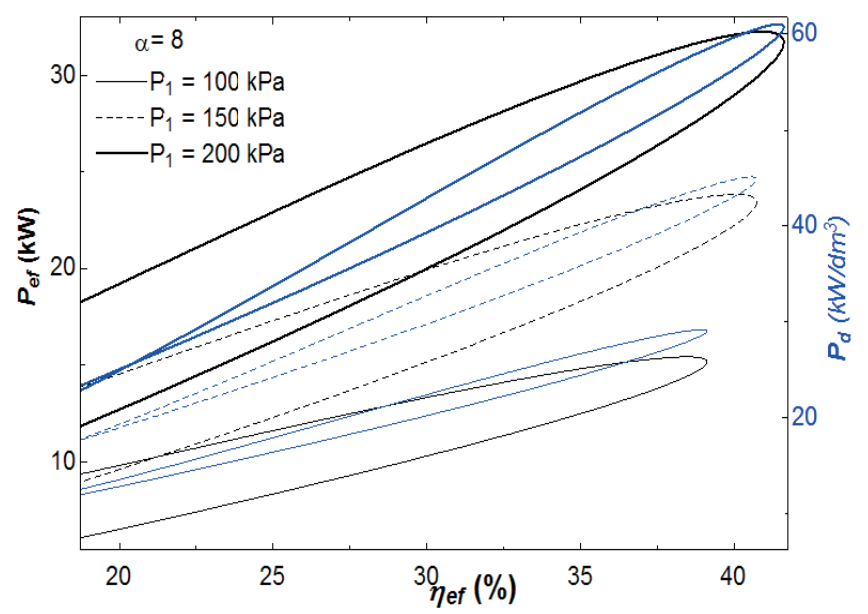

Fig. 11. The variation of $P_{e f}-P_{d}-\eta_{e f}$ with respect to $P 1$.

The influences of the ratio of bore to stroke $(\mathrm{d} / \mathrm{L})$ on the performance characteristics are demonstrated in Fig.12. It is clear that the performance characteristics rise with raising $\mathrm{d} / \mathrm{L}$ due to increasing engine dimensions.

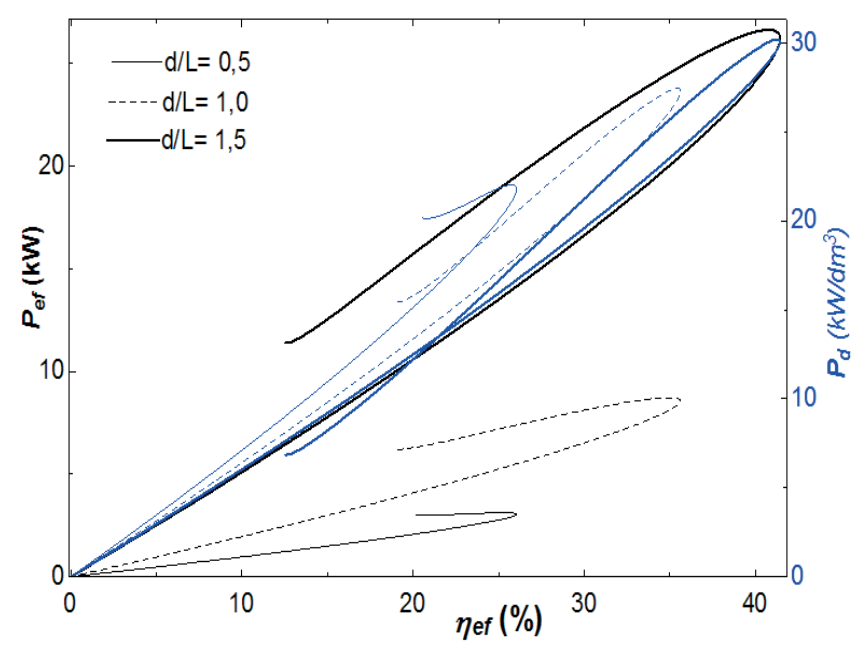

Fig. 12. The variation of $P_{e f}-P_{d}-\eta_{e f}$ with respect to $d / L$.

Figs. 13a-c show the effects of $d / L$ on the performance characteristics at constant cylinder volume for three different conditions. Fig. 13a is plotted at constant CTR and stroke length condition. The performance parameters enhance to a determined value and then begin to abate with rising $\mathrm{d} / \mathrm{L}$. Fig. $13 \mathrm{~b}$ is plotted at constant equivalence ratio and stroke length condition. The performance parameters raise with increasing d/L. Fig. 13c is plotted at constant equivalence ratio and compression ratio condition. This figure shows similar characteristics to previous figure. Same increase trend can be observed. 

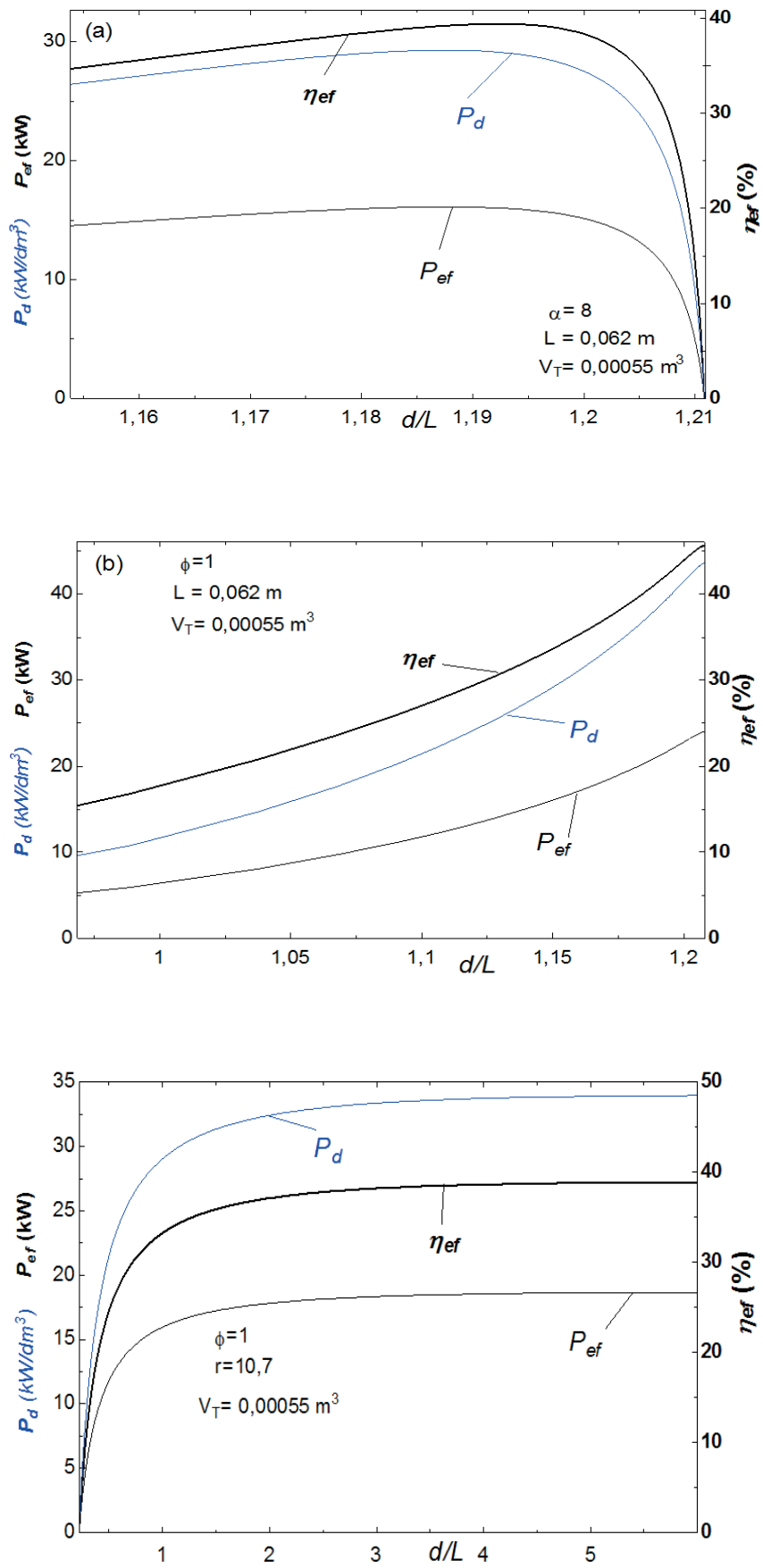

Fig. 13. The effects of $d / L$ on $P_{e f}-P_{d}-$ ef variation at constant a) $\alpha$ and $L$, b) $\phi$ and $L, c) \phi$ and $r$

Figs. 14a-b demonstrate the influence of $\mathrm{r}$ on losses as fuel's energy for two different conditions. Fig. 14a is depicted at constant cycle temperature ratio condition. Incomplete combustion loss $\left(\mathrm{L}_{\mathrm{ic}}\right)$ and exhaust energy loss $\left(\mathrm{L}_{\mathrm{ex}}\right)$ decrease while heat transfer loss $\left(\mathrm{L}_{\mathrm{ht}}\right)$ increase and friction loss $\left(\mathrm{L}_{\mathrm{fr}}\right)$ remains constant with increasing $r$. Total cylinder volume and equivalence ratio change with respect to changing of $r$ at this condition. $L_{i c}$ is related to equivalence ratio and it changes with changing equivalence ratio. It decreases as fuel energy input decreases with increasing r. Fig. $14 \mathrm{~b}$ is depicted at constant equivalence ratio condition. $\mathrm{L}_{\mathrm{ic}}$ and $\mathrm{L}_{\mathrm{fr}}$ are constant, $\mathrm{L}_{\mathrm{ht}}$ increases and $\mathrm{L}_{\mathrm{ex}}$ decreases with respect to rising compression ratio. Cylinder volume enhances with increasing $r$, hence $\mathrm{L}_{\mathrm{ht}}$ increases. Useful work increases with increasing $\mathrm{r}$ and so $\mathrm{L}_{\mathrm{ex}}$ abates. $\mathrm{L}_{\mathrm{fr}}$ changes with respect to stroke and speed which are constant at both of these conditions. Therefore, $\mathrm{L}_{\mathrm{ic}}$ does not change.
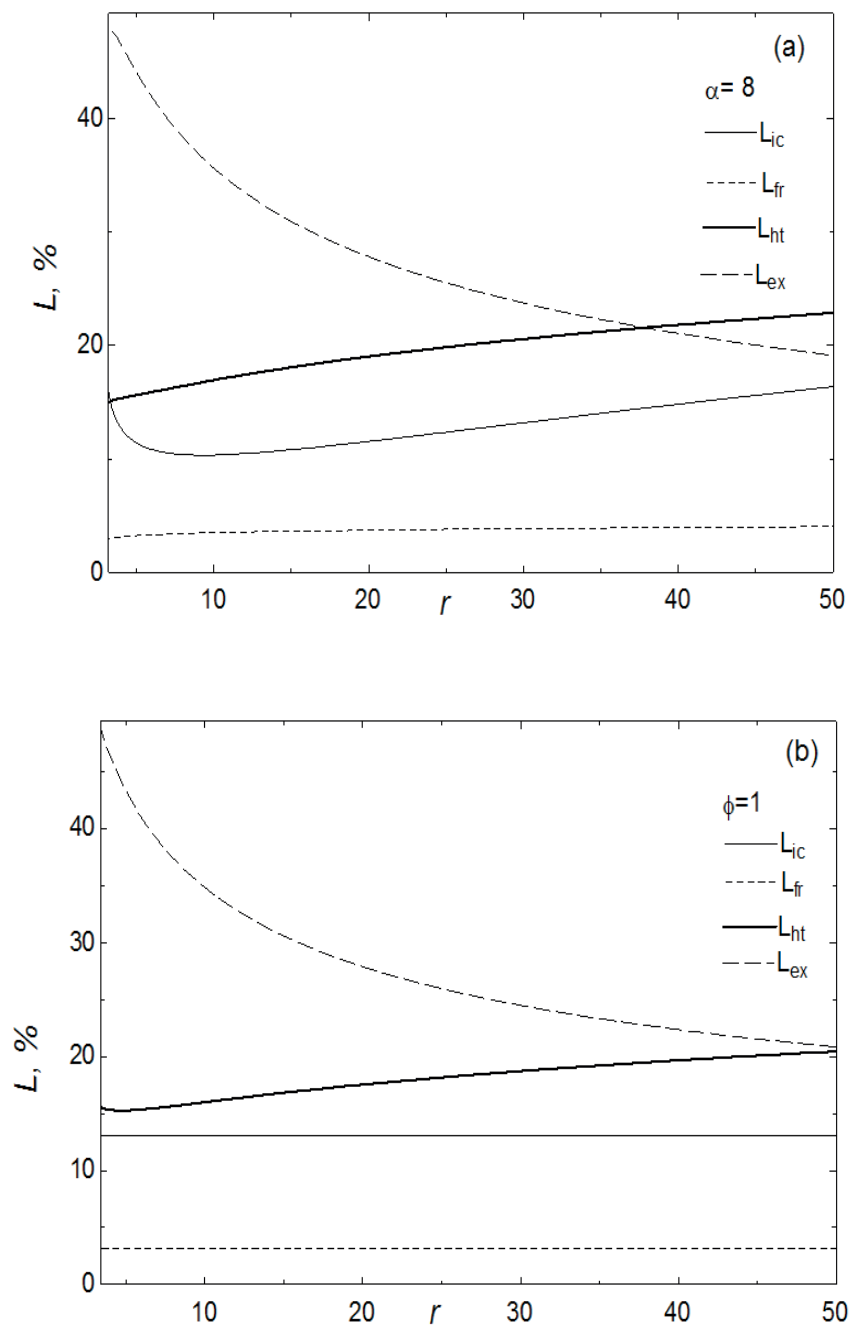

Fig. 14. The variation of energy loss percentages with respect to $r$ for constant a) $\alpha$ and b) $\phi$.

Figs. 15a-c demonstrate the effects of RGF on the performance parameters for three different conditions. The figures are plotted at constant cycle temperature condition, constant equivalence ratio condition and at constant compression ratio condition. Similar trends are seen for all conditions. The performance characteristics abate with increasing RGF as expected. Because, intake temperature rises and air mass introduced into the cylinder diminishes with increasing RGF. 

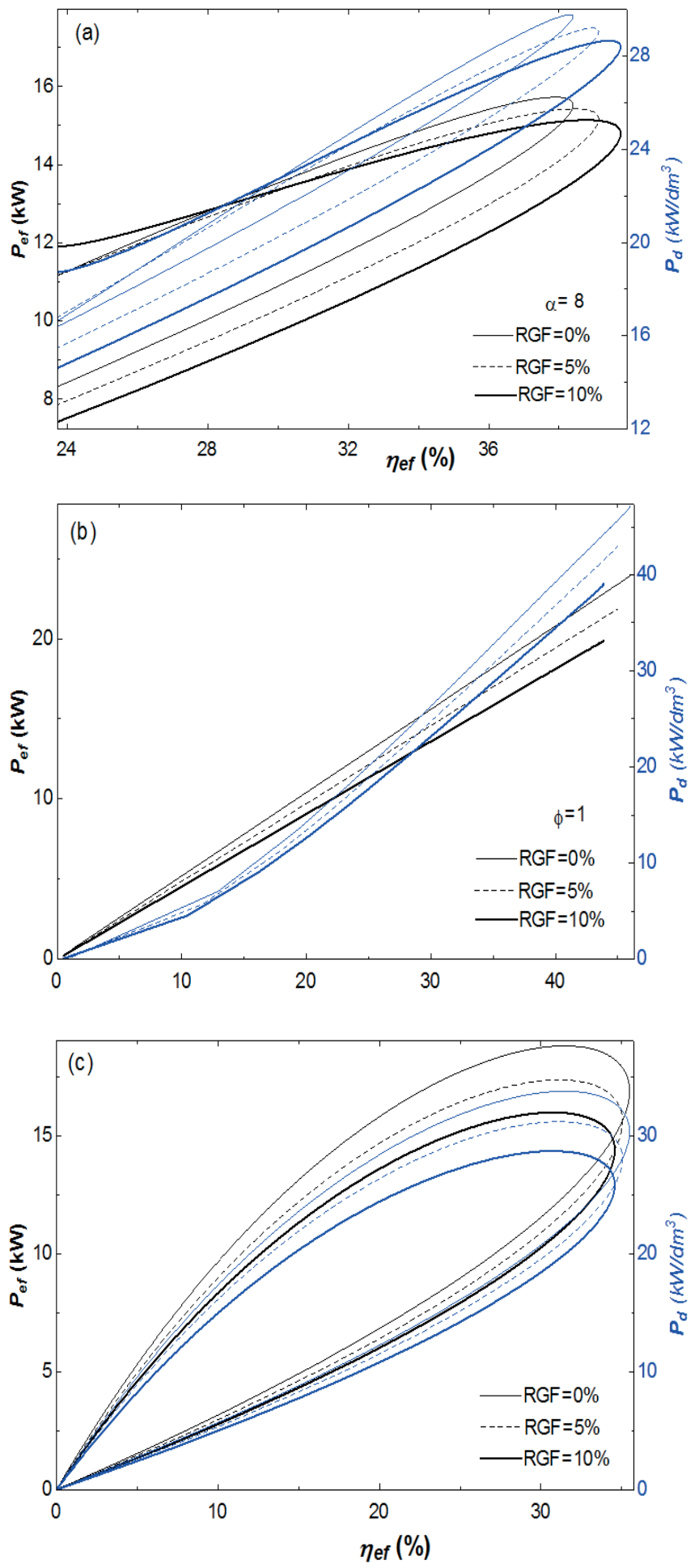

Fig. 15. The effects of $R G F$ on $P_{e f}-P_{d}-\eta_{e f}$ variation at constant a) $\left.\left.\alpha, b\right) \phi, c\right) r$.

In this work, the curves are obtained with respect to the variation of the equivalence ratio. The operating points of the engine can be determined to acquire the maximum efficiency or maximum power conditions.

\section{CONCLUSION}

The influences of the engine design and operating parameters on the performance characteristics and energy losses of a diesel engine have been investigated using a FTTM. Comprehensive parametrical comparisons have been performed. In the parametrical studies, the influences of CTR $(\boldsymbol{\alpha}), \operatorname{CPR}(\lambda)$, friction coefficient $(\boldsymbol{\mu})$, engine speed $(\mathrm{N})$, mean piston speed $\left(\bar{S}_{p}\right)$, stroke length (L), intake temperature (T1), intake pressure $\left(\mathrm{P}_{1}\right)$, equivalence ratio $(\phi)$, compression ratio $(r)$, bore-stroke length ratio $(d / L)$ and residual gas fraction ( $R G F$ ) on the performance parameters have been examined. The results show that the performance parameters increase with increasing cycle temperature ratio $(\alpha)$, cycle pressure ratio $(\lambda)$ and intake pressure $\left(\mathrm{P}_{1}\right)$. The engine performance abates with friction coefficient $(\boldsymbol{\mu})$. On the other hand, the $\mathrm{PO}, \mathrm{PD}$ and $\mathrm{EE}$ rise with rising mean piston speed for constant engine speed conditions. However, as the PO and $\mathrm{PD}$ increase, the EE diminishes with rising mean piston speed for constant stroke length conditions. While the PO and $\mathrm{PD}$ increase, the EE abates with rising stroke length and engine speed. The PO, PD and EE increase up to a determined value and then begin to abate with rising equivalence ratio and compression ratio. The energy losses with respect to heat transfer increase, as incomplete combustion and exhaust output losses decrease with increasing compression ratio for constant $\alpha$ conditions. At this condition, friction losses are constant. However, the losses dependent on friction and incomplete combustion are constant, while exhaust output losses decrease and heat transfer losses increase at the constant equivalence ratio conditions. Scientifically valuable results have been obtained and they can be used by eco-friendly engine designers.

\section{REFERENCES}

1. Al-Sarkhi, A., Akash, B.A. \& Jaber, J.O., 2002. Efficiency of Miller Engine at Maximum Power Density. Int Commun Heat Mass, 29, pp.1159-1167.

2. Al-Sarkhi, A., Jaber, J.O., Probert, S.D., 2006. Efficiency of a Miller engine. Appl Energ, 83,pp.343-351.

3. Al-Sarkhi, A., Al-Hinti, I., Abu-Nada, E., Akash, B., 2007. Performance evaluation of irreversible Miller engine under various specific heat models. Int Commun Heat Mass, 34, pp.897-906.

4. Anderson, M., Assanis, D., Filipi, Z., 1998. First and second law analyses of a naturally-aspirated, Miller cycle, SI engine with late intake valve closure. SAE Technical Paper Series, 980889, pp.1-16. 
5. Benajes, J., Molina, S., Novella, R., Belarte, E., 2014. Evaluation of massive exhaust gas recirculation and Miller cycle strategies for mixing-controlled low temperature combustion in a heavy duty diesel engine. Energy, 71, 355-366.

6. Chen, L., Wu, C. \& Sun, F.R., 1999. Finite time thermodynamic optimization or entropy generation minimization of energy systems. J. Non-Equilib. Thermodyn., 24(4), pp.327-359.Chen, L. \& Sun, F.R., 2004. Advances in Finite Time Thermodynamics: Analysis and Optimization. New York: Nova Science Publishers,

7. Chen, L., 2005. Finite-Time Thermodynamic Analysis of Irreversible Processes and Cycles. Beijing: High Education Press. (in Chinese).

8. Chen, L., Ge, Y., Sun, F., \& Wu, C., 2006. Effects of heat transfer, friction and variable specific heats of working fluid on performance of an irreversible Dual cycle. Energy Convers. Manage., 47(18/19), pp.3224-3234.

9. Chen, L., Ge, Y., Sun, F., \& Wu, C., 2010. The performance of a Miller cycle with heat transfer, friction and variable specific heats of working fluid. Termotehnica, 14(2), pp.24-32.

10. Chen, L., Ge, Y., Sun, F., \& Wu, C., 2011. Finite time thermodynamic modeling and analysis for an irreversible Miller cycle. Int. J. Ambient Energy, 32(2), pp.87-94.

11. Chen, L. \& Xia, S.J., 2016. Generalized Thermodynamic Dynamic-Optimization for Irreversible Processes. Beijing: Science Press. (in Chinese).

12. Chen, L., Xia, S.J. \& Li, J., 2016. Generalized Thermodynamic Dynamic-Optimization for Irreversible Cycles. Beijing: Science Press. (in Chinese).

13. Clarke, D., \& Smith, W.J., 1997. Simulation, implementation and analysis of the Miller cycle using an inlet control rotary valve, Variable valve actuation and power boost. SAE Special Publications, 1258(970336), pp. 61-70.

14. Ebrahimi, R., 2011a. Thermodynamic modeling of performance of a Miller cycle with engine speed and variable specific heat ratio of working fluid. Computers and Mathematics with Applications, 62, pp.2169-2176.

15. Ebrahimi, R., 2011b. Effects of mean piston speed, equivalence ratio and cylinder wall temperature on performance of an Atkinson engine. Mathematical and Computer Modelling, 53, pp.1289-1297.

16. Ebrahimi, R., 2012. Performance analysis of an irreversible Miller cycle with considerations of relative air-fuel ratio and stroke length. Applied Math Modeling, 36, pp.4073-4079.
17. EES Academic Professional Edition, 2016. V.10.112-3D, USA, F-Chart Software.

18. Ferguson, C.R., 1986. Internal combustion engines applied thermosciences. New York: John Wiley \& Sons Inc.

19. Gahruei, M.H,, Jeshvaghani, H.S., Vahidi, S., \& Chen, L., 2013. Mathematical modeling and comparison of air standard Dual and Dual-Atkinson cycles with friction, heat transfer and variable specific-heats of the working fluid. Applied Mathematical Modelling, 37(12-13), pp.7319-7329.

20. Ge, Y., Chen, L., Sun, F., \& Wu, C., 2005a. Reciprocating heat-engine cycles. Appl. Energy, 81, pp.397-408.

21. Ge, Y., Chen, L., Sun, F., \& Wu, C., 2005b. Effects of heat transfer and friction on the performance of an irreversible air-standard Miller cycle. Int. Comm. Heat Mass Transfer, 32(8), pp.1045-1056.

22. Ge, Y., Chen, L., Sun, F., \& Wu, C., 2005c. Effects of heat transfer and variable specific heats of working fluid on performance of a Miller cycle. Int. J. Ambient Energy, 26(4), pp.203-214.

23. Ge, Y., Chen, L., Sun, F., \& Wu, C., 2008. Finite-Time Thermodynamic Modelling and Analysis of an Irreversible Otto-Cycle. Appl Energy, 85, pp.618-24.

24. Ge, Y., Chen, L., \& Sun, F., 2009. Finite time thermodynamic modeling and analysis for an irreversible Dual cycle. Math. Comput. Model., 50(1-2), pp.101-108.

25. Ge, Y., Chen, L., \& Sun, F., 2016. Progress in finite time thermodynamic studies for internal combustion engine cycles. Entropy, 18(4), pp.139.

26. Gonca, G., 2016a. Comparative performance analyses of irreversible OMCE (Otto Miller cycle engine)-DiMCE (Diesel miller cycle engine)-DMCE (Dual Miller cycle engine). Energy, 109, pp.152-159.

27. Gonca, G., 2016b. Thermodynamic analysis and performance maps for the irreversible Dual-Atkinson cycle engine (DACE) with considerations of temperaturedependent specific heats, heat transfer and friction losses. Energy Conversion and Management, 111, pp.205-216.

28. Gonca, G., 2017a. Thermo-Ecological Analysis of Irreversible Dual-Miller Cycle (DMC) Engine Based on the Ecological Coefficient of Performance (ECOP) Criterion, Iran J Sci Technol Trans Mech Eng (In press.), doi:10.1007/s40997-016-0060-2.

29. Gonca, G., 2017b. Exergetic and ecological performance analyses of a gas turbine system with two intercoolers and two re-heaters. Energy, 124, pp. 579-588. 
30. Gonca, G., 2017c. Effects of engine design and operating parameters on the performance of a spark ignition (SI) engine with steam injection method (SIM). Applied Math. Model., 44, pp. 655-675.

31. Gonca, G., 2017d. Performance Analysis of A Spark Ignition (SI) Otto Cycle (OC) Gasoline Engine Under Realistic Power (RP) and Realistic Power Density (RPD) Conditions. Journal of Polytechnic, 20(2), pp.475-486.Gonca, G., Sahin, B., Ust, Y., \& Parlak A., 2013a. A study on late intake valve closing Miller cycled diesel engine. Arab J Sci Eng, 38, pp.383-393.

32. Gonca, G., Sahin, B., \& Ust, Y., 2013b. Performance maps for an air-standard irreversible dual-Miller cycle (DMC) with late inlet valve closing (LIVC) version. Energy, 5, pp.285-290.

33. Gonca, G., \& Sahin, B., 2014. Performance Optimization of an Air-Standard Irreversible Dual-Atkinson Cycle Engine Based on the Ecological Coefficient of Performance Criterion. The Scientific World Journal, 815787, pp.1-10.

34. Gonca, G., Sahin, B., Ust, Y., Parlak, A., \& Safa, A., 2015a. Comparison of Steam Injected Diesel Engine and Miller Cycled Diesel Engine By Using Two Zone Combustion Model. J Energy Inst,88(1), pp.43-52.

35. Gonca, G., Sahin, B., Parlak, A., Ust, Y., Ayhan, V., Cesur, I., \& Boru, B., 2015b. Theoretical and experimental investigation of the Miller cycle diesel engine in terms of performance and emission parameters. Appl.Energy, 138, pp.11-20.

36. Gonca, G., Sahin, B., \& Ust, Y., 2015c. Investigation of heat transfer influences on performance of air-standard irreversible dual-Miller cycle. J. Thermophys Heat Trans, 29(4), pp.678-683.

37. Gonca, G., Sahin, B., Parlak, A., Ayhan, V., Cesur, I., \& Koksal, S., 2015d. Application of the Miller cycle and turbo charging into a diesel engine to improve performance and decrease NO emissions. Energy, 93, pp.795-800.

38. Gonca, G., Sahin, B., Ust, Y., \& Parlak, A., 2015 e. Comprehensive performance analyses and optimization of their reversible thermodynamic cycle engines (TCE) under maximum power (MP) and maximum power density (MPD) conditions. Appl Thermal Eng, 85, pp.9-20.

39. Gonca, G., \& Sahin, B., 2016. The influences of the engine design and operating parameters on the performance of a turbocharged and steam injected diesel engine running with the Miller cycle. Applied Mathematical Modelling, 40, pp.3764-3782.
40. Gonca, G., \& Sahin, B., 2017a. Effect of turbo charging and steam injection methods on the performance of a Miller cycle diesel engine (MCDE). Applied Thermal Engineering, 118, pp.138-146.

41. Gonca, G., \& Sahin, B., 2017b. Thermo-ecological performance analysis of a Joule-Brayton cycle (JBC) turbine with considerations of heat transfer losses and temperature-dependent specific heats. Energy Conversion and Management 138, pp. 97-105.

42. Gonca, G., Sahin, B., Parlak, A., Ayhan, V., Cesur, I., \& Koksal, S., 2017. Investigation of the effects of the steam injection method (SIM) on the performance and emission formation of a turbocharged and Miller cycle diesel engine (MCDE). Energy, 119, pp.926-937.

43. Hohenberg, G., 1979. Advanced Approaches for Heat Transfer Calculations. SAE, 790825.

44. Imperato, M., Kaario, O., Sarjovaara, T., Larmi, M., 2016. Split fuel injection and Miller cycle in a large-bore engine. Applied Energy, 162, pp.289-297.

45. Li, T., Gao, Y., Wang, J., \& Chen, Z., 2014. The Miller cycle effects on improvement of fuel economy in a highly boosted, high compression ratio, direct-injection gasoline engine: EIVC vs LIVC. Energy Convers and Manage, 79, pp.59-65.

46. Li, T., Wang, B., Zheng, B., 2016. A comparison between Miller and five-stroke cycles for enabling deeply downsized, highly boosted, spark-ignition engines with ultra expansion. Energy Conversion and Management, 123, pp.140-152.

47. Lin, J., Chen, L., Wu, C., \& Sun, F., 1999. Finite-Time Thermodynamic Performance of a Dual Cycle. Int J Energy Res, 23(9), pp.765-772.

48. Lin, J.C., \& Hou, S.S., 2008. Effects of Heat Loss As Percentage of Fuel's Energy, Friction And Variable Specific Heats Of Working Fluid On Performance of Air Standart Otto Cycle. Energ Convers Manage, 49, pp.1218-27.

49. Luo, Q., Sun, B., 2016. Effect of the Miller cycle on the performance of turbocharged hydrogen internal combustion engines. Energy Conversion and Management, 123, pp.209-217.

50. Martins, M.E.S., \& Lanzanova, T.D.M., 2015. Full-load Miller cycle with ethanol and EGR: Potential benefits and challenges. Applied Thermal Engineering, 90, 274-285.

51. Mikalsen, R., Wang, Y.D., \& Roskilly, A.P., 2009. A comparison of Miller and Otto cycle natural gas engines for small scale CHP applications. Applied Energy, 86, pp.922-927. 
52. Miller, R.H., 1947. Supercharging and internal cooling cycle for high output, Transactions of ASME, 69, pp.453-457.

53. Miller, R.H., \& Lieberherr, H.U., 1957. The Miller supercharging system for diesel and gas engines operating characteristics, CIMAC, Proceedings of the 4th International Congress on Combustion Engines, Zurich, June 15-22, pp. 787-803.

54. Mousapour, A., Hajipour, A., Rashidi, M.M., Freidoonimehr, N., 2016. Performance evaluation of an irreversible Miller cycle comparing FTT (finite-time thermodynamics) analysis and ANN (artificial neural network) prediction. Energy, 94, pp.100-109.

55. Okamoto, K., Zhang, F.R., Morimoto, S., \& Shoji, F., 1998. Development of a high-performance gas engine operating at a stoichiometric condition - effect of Miller cycle and EGR, Proceedings of CIMAC Congress, Copenhagen, pp. 1345-1360.

56. Rashidi, M.M., Mousapour, \& A., Hajipour, A., 2014. The effects of heat transfer on the exergy efficiency of an airstandard Otto cycle. Heat Mass Transfer, 50, pp.1177-83.

57. Rashidi, M.M., \& Hajipour, A., 2013. Comparison of Performances of Air-Standard Atkinson, Diesel and Otto Cycles with Constant Specific Heats. Int J Advanced Design and Manufacturing Technology, 6,pp.57-62.

58. Rashidi, M.M., Hajipour, A., Mousapour, A., Ali, M., Xie, G., \& Freidoonimehr, N., 2014. First and Second-Law Efficiency Analysis and ANN Prediction of a Diesel Cycle with Internal Irreversibility, Variable Specific Heats, Heat Loss, and Friction Considerations. Advances in Mechanical Engineering, 359872, pp.1-16.

59. Rashidi, M.M., Hajipour, A., \& Fahimirad, A., 2014. First and Second-Laws Analysis of an Air-Standard Dual Cycle With Heat Loss Consideration. International Journal of Mechatronics, Electrical and Computer Technology, 4, pp.315-332.

60. Rashidi, M.M., Hajipour, A., \& Baziar, P., 2014. Influence of Heat Loss on the Second-Law Efficiency of an Otto Cycle. International Journal of Mechatronics, Electrical and Computer Technology, 4, pp.922-933.

61. Rinaldini, C.A., Mattarelli, E., \& Golovitchev, V.I., 2013. Potential of the Miller cycle on a HSDI diesel automotive engine. Applied Energy,112, pp.102-19.

62. Shimogata, S., Homma, R., Zhang, F.R., Okamoto, K., \& Shoji, F., 1997. Study on Miller cycle gas engine for co-generation systems-numerical analysis for improvement of efficiency and power. SAE Paper No. 971709, pp. 61-67.
63. Stebler, H., Weisser, G., Horler, H., \& Boulouchos, K., 1996. Reduction of NOx emissions of D.I. Diesel engines by application of the Miller-system: an experimental and numerical investigation, SAE Paper No. 960844, pp. $1238-1248$

64. Ust, Y., Arslan, F., Ozsari, I., \& Cakir, M., 2015. Thermodynamic performance analysis and optimization of DMC (Dual Miller Cycle) cogeneration system by considering exergetic performance coefficient and total exergy output criteria. Energy, 90, pp.552-559.

65. Wang, W.H., Chen, L., Sun, F., \& Wu, C., 2002. The effects of friction on the performance of an air standard Dual cycle. Exergy, An Int. J., 2(4), pp.340-344.

66. Wang, Y.D., \& Ruxton, T., 2004. An experimental investigation of NOx emission reduction from automotive engine using the miller cycle. Proceedings of ICEF2004, ASME Internal Combustion Engine Division, Fall Technical Conference, Long Beach, CA, USA, October 24-27.

67. Wang, Y., Zeng, S., \& Huang, J., 2005. Experimental investigation of applying Miller cycle to reduce $\mathrm{NOx}$ emission from diesel engine. Proc. IMechE, Part A: J. Power and Energy, 219, pp.631-638.

68. Wang, Y., Lin, L., \& Roskilly, A.P., 2007. An analytic study of applying Miller cycle to reduce NOx emission from petrol engine. Appl Therm Eng, 27, pp.1779-1789.

69. Wang, Y., Lin, L., \& Zeng, S., 2008. Application of the Miller cycle to reduce NOx emissions from petrol engines. Appl. Energy, 85, pp.463- 474.

70. Wang, Y., Zu, B., X,u Y., Wang, Z., Liu, J., 2016. Performance analysis of a Miller cycle engine by an indirect analysis method with sparking and knock in consideration. Energy Conversion and Management, 119, pp.316-326.

71. Wu, C., Chen, L.G. \& Chen, J.C., 1999. Recent Advances in Finite Time Thermodynamics. New York: Nova Science Publishers,

72. Wu, C., Puzinauskas, P.V. \& Tsai, J.S., 2003. Performance analysis and optimization of a supercharged Miller cycle Otto engine. Appl Therm Eng, 23, pp.511-521.

73. Tavakoli, S., Jazayeri, S.A., Fathi, M., Jahanian, O., 2016. Miller cycle application to improve lean burn gas engine performance. Energy, 109, pp.190-200.

74. Zhao, Y., \& Chen, J., 2007. Performance analysis of an irreversible Miller heat engine and its optimum criteria. Appl Therm Eng, 27, pp.2051-2058.Zhao, J., 2017. Research and application of over-expansion cycle (Atkinson and Miller) engines-A review. Applied Energy, 185, pp.300-319. 
75. Zhu, S., Deng, K., Liu, S., Qu, S., 2015. Comparative analysis and evaluation of turbocharged Dual and Miller cycles under different operating conditions. Energy, 93, pp.75-87.

\section{CONTACT WITH THE AUTHOR}

\section{Guven Gonca}

e-mail:guvengca@gmail.com

Yildiz Technical University

Barbaros, 34349 Istanbul

TURKEY 